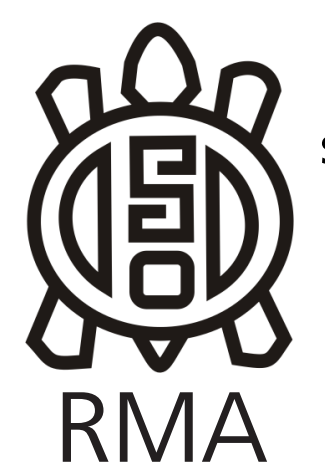

Arqueología

\title{
Análisis estadístico de puntas de proyectil en el sudoeste de la provincia de Buenos Aires (Argentina)
}

\author{
Statistical analysis of projectile points in the southwest of the province of
} Buenos Aires (Argentina)

\author{
Rodrigo Vecchi*, Alicia B. Hernández** y Liliana García*** \\ ${ }^{*}$ CONICET-Departamento de Humanidades, Universidad Nacional del Sur. \\ E-mail: druyer79@hotmail.com. \\ **Departamento de Matemática, Universidad Nacional del Sur. \\ Email: aliciahe@criba.edu.ar \\ ***Departamento de Matemática, Universidad Nacional del Sur. \\ Email: Igarcia@uns.edu.ar
}

\begin{abstract}
Resumen
Con el objetivo de identificar los sistemas de armas utilizados en el sudoeste bonaerense durante el Holoceno se analiza la variabilidad de puntas de proyectil recuperadas en nueve sitios arqueológicos. Sobre la base de variables métricas se realizó la segmentación del conjunto en grupos mediante el análisis estadístico, descriptivo e inferencial, aplicando métodos univariados y multivariados. La relación entre largo, ancho y espesor permitió identificar cuatro grupos estadísticos y, a partir de los mismos, proponer la presencia de diferentes sistemas de armas. El relevamiento de las diferentes morfologías de limbos y bases posibilitó reconocer siete tipos morfológicos. El análisis tecnotipológico permitió reconocer las distintas técnicas de formatización empleadas, la presencia de mantenimiento y las diferentes materias primas utilizadas para su confección.
\end{abstract}

Palabras clave: Cazadores-recolectores; Puntas de proyectil; Análisis estadístico univariado y multivariado; Variables de diseño; Sistemas de armas.

\begin{abstract}
In order to identify the weapons systems used along the Holocene in Southwest Buenos Aires Province, the variability of projectile points recovered at nine archaeological sites is analyzed. Univariate and multivariate statistical, descriptive and inferential analysis of the metric variables, resulted in the recognition of four statistical groups, based on the relationship between length, width and thickness. Seven morphological groups were identified based on the different morphologies of limbs and bases. The result of techno-typological analysis allowed us to identify different manufacturing techniques, the presence of maintenance and the different raw material used.
\end{abstract}

Keywords: Hunter-gatherers; Projectile Points; Univariate and Multivariate statistical analysis; Design variables; Weapon systems.

\section{Introducción}

Las puntas líticas son el remanente perdurable de un artefacto conformado por varias tecnounidades, que sólo en la mayoría de los casos puede estudiarse de manera indiciaria (Aschero y Martínez, 2001; Banegas, Gómez Otero, Goye y Ratto, 2014; Cardillo y Alberti, 2015; Churchill, 1993; Escola, 2014; Flegenheimer, Martínez y Colombo, 2010; Knecht, 1997; Martínez, Caria, Mauri y Mercuri, 2010; Ratto, 1991; entre otros). Para su abordaje, un buen punto de partida consiste en la realización de estudios tecno-morfológicos de artefactos procedentes de microrregiones y relacionar sus diseños con las asociaciones contextuales y cronológicas (Aschero, 1988; Aschero y Martínez, 2001). La descripción y clasificación de las puntas líticas permiten reconocer ciertas tendencias o patrones generales respecto a diferentes aspectos de los grupos cazadoresrecolectores, tales como los sistemas de armas utilizados, la variabilidad de grupos tipológicos, la gestión de los recursos líticos, etc. (Aschero y Martínez, 2001; Hughes, 1998; Shott, 1993 y 1997; Thomas, 1978).

En la pampa bonaerense, este tipo de artefacto ha sido hallado en sitios con diversa cronología, desde las primeras ocupaciones (ca. 12.000 años AP) hasta 
momentos previos al contacto con los europeos y en las diferentes áreas de la subregión (ver síntesis en Berón y Politis, 1997; Politis, 2012; Politis y Madrid, 2001; Valverde y Martucci, 2004; entre otros). En aquellos contextos estratigráficos datados, estas puntas muestran variaciones en su diseño y tamaño a lo largo del Holoceno. Las puntas más tempranas (desde fines del Pleistoceno hasta el Holoceno temprano) son pedunculadas ("cola de pescado"), y fueron reemplazadas luego por otras triangulares apedunculadas de diferentes tamaños (Valverde y Martucci, 2004; Politis, 2012; Escola, 2014; Vigna, González y Weitzel, 2014; Barros, Heider, Alvarez, Kaufmann y Bellinzoni, 2018; González, Escoteguy, Salemme, Frére, Weitzel y Vecchi, 2021; Kaufmann, Álvarez, Messineo, Barros, Bonomo y Heider, 2021; entre otros). Su presencia en una importante cantidad de sitios en la región generó interés sobre los sistemas de armas y sus componentes (ver Flegenheimer et al., 2010), las características tecno-tipológicas (Escola, 2014; Valverde y Martucci, 2004), la biografía de estos objetos (Vigna et al., 2014) y sobre su manufactura y uso (Flegenheimer $e t$ al., 2010; Weitzel, Flegenheimer, Martínez y Colombo, 2014).

En cuanto al sector de estudio, en la llanura surventánica (sensu González Uriarte, 2002), el hallazgo de puntas de proyectil ha sido mencionado en la descripción de contextos líticos de sitios y en trabajos de síntesis (entre otros: Austral, 1968; Conlazo, 1983; Oliva, Ávila, Ayuso, Catella y Gallego, 2006; Bayón, Pupio, Frontini, Vecchi y Scabuzzo, 2010; Vecchi, Frontini y Bayón, 2013; Frontini y Bayón, 2017a). En este trabajo se analizan las puntas de proyectil provenientes de nueve sitios de dicho sector, a fin de organizar la variabilidad de puntas del área con la finalidad de inferir los sistemas de armas que pudieran haber sido utilizados. Para ello, en primer término, se registraron las variables métricas (largo, ancho, espesor y peso) y en base a éstas se realizó la segmentación del conjunto en grupos mediante análisis estadístico, descriptivo e inferencial, aplicando métodos univariados y multivariados. En segundo término, se identificaron los diferentes tipos de diseños, sus características tecno-tipológicas y se analizaron las estrategias de abastecimiento de las materias primas (Aschero, 1975, 1983 y 1988; Hocsman, Martínez, Aschero y Calisaya, 2012; Martínez et al., 2010; Messineo y Barros, 2015: entre otros).

\section{La microrregión y los sitios}

La microrregión se ubica en el sudoeste de la provincia de Buenos Aires. Está atravesada por varios cursos de agua, entre ellos los ríos Sauce Grande, Sauce Chico y el arroyo Napostá Grande, que nacen en las Sierras Australes y desembocan en el océano Atlántico. El clima es templado, con sequías periódicas y fuertes vientos (Bróndolo et al., 1994). Estas características climáticas afectaron al registro arqueológico. Muchos contextos han quedado expuestos en superficie por la dinámica eólica y se formaron palimpsestos, especialmente en los entornos con presencia de médanos (Bróndolo et al., 1994).

La disponibilidad de rocas es altamente localizada y siempre bajo la forma de rodados. Rocas cuarcíticas, cuarzos y subarcosas se encuentran en depósitos gravosos en los valles fluviales y en parte de la costa atlántica afectada por cambios en la desembocadura del río Sauce Grande ocurridos desde el Pleistoceno (Bayón y Zavala, 1997). Las rocas basálticas (andesitas, basandesitas y basaltos; Frisicale comunicación personal 2016) y los sílices, de características variadas, se encuentran entre los rodados dispersos en la playa, transportados por las corrientes marinas desde las bocas de los ríos Colorado y Negro (Bayón y Zavala, 1997; Bonomo y Prates, 2014). Otras materias primas presentes, en el registro arqueológico, como la riolita y el chert silíceo, sólo están disponibles en las Sierras Australes y en las llanuras inmediatamente aledañas (Oliva y Moirano, 1997; Bayón,

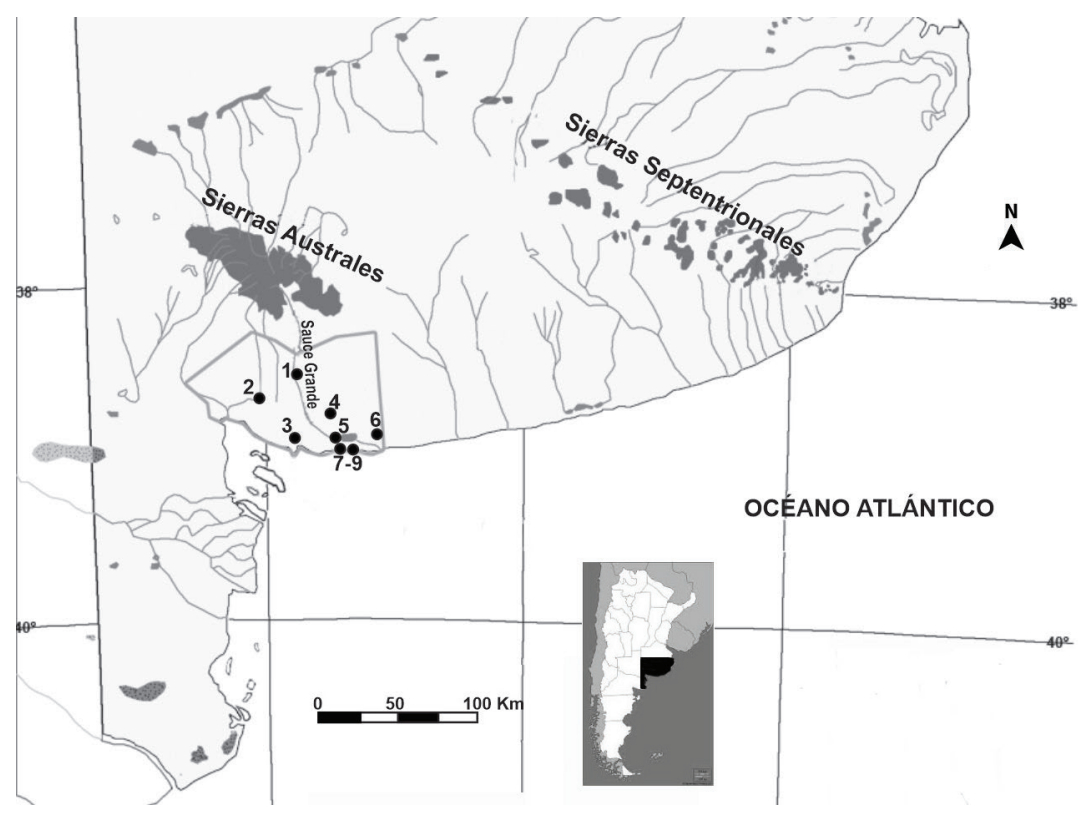

Figura 1: Ubicación de los sitios analizados. Referencias: 1: Paso Mayor; 2: Paso Vanoli; 3: Punta Alta I; 4: Laguna Toro; 5: Puente de Fierro; 6: Laguna Faro; 7-9: El Tiburonero, El Americano y Las Dunas.

Figure 1: Location of the analyzed sites. References: 1: Paso Mayor; 2: Paso Vanoli; 3: Punta Alta l; 4: Laguna Toro; 5: Puente de Fierro; 6: Laguna Faro; 7-9: El Tiburonero, El Americano y Las Dunas. 
Vecchi y Pupio, 2010; entre otros), mientras que las ortocuarcitas del Grupo Sierras Bayas (OGSB) y la ftanita se localizan en las Sierras Septentrionales, a unos 300 $\mathrm{km}$ al noreste del área bajo estudio (Flegenheimer, Kain, Zárate y Barna, 1996; Barros y Messineo, 2004; Colombo, 2013; entre otros).

La mayor parte de los sitios reconocidos en la microrregión presentan contextos líticos que incluyen puntas de proyectil (Figura 1):

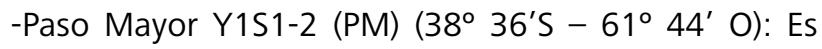
un sitio en estratigrafía con una importante colección de superficie, ubicado en el valle medio inferior del río Sauce Grande, en el partido de Coronel Pringles (Austral, 1968; Bayón et al., 2010). Presenta niveles superpuestos: los inferiores, datados entre ca. 5900 y 3800 años AP y los superiores, datados entre ca. 2800 y 700 años AP. Ambos conjuntos se interpretaron como campamentos residenciales reocupados periódicamente, con presencia de artefactos líticos, restos óseos, malacológicos y presencia de entierros en los Niveles Superiores asociados a tiestos cerámicos (Bayón et al. 2010; Scabuzzo, Frontini, Vecchi y Bayón, 2016). En la localidad fueron recuperadas 44 puntas.

-Puente de Fierro (PF) (38 $\left.56^{\prime} 17^{\prime \prime} \mathrm{S}-61^{\circ} 27^{\prime} 05^{\prime \prime} \mathrm{O}\right)$ : El sitio Puente de Fierro se emplaza en la margen izquierda del río Sauce Grande (partido de Monte Hermoso), a unos $1000 \mathrm{~m}$ de la desembocadura del río en la laguna homónima, donde se conforma un humedal. Es un sitio en estratigrafía interpretado como un campamento residencial datado entre $2532 \pm 54$ y $2000 \pm 80$ años $A P$, en el que se recuperaron artefactos líticos, malacológicos, cerámicos y restos arqueofaunísticos (Bayón y Frontini, 2016; Frontini y Bayón, 2015, 2017 y 2017a). La colección del sitio presenta 4 puntas de proyectil.

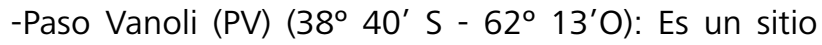
en estratigrafía ubicado en el valle inferior del arroyo Napostá Grande, en inmediaciones de la ciudad de Bahía Blanca. Interpretado como un campamento residencial, presenta dataciones de $630 \pm 60$ y $714 \pm 53$ años AP (Austral y García Cano, 1999; Austral y Pérez Amat, 1985; Vecchi et al., 2013). La colección está integrada por artefactos líticos, tiestos cerámicos, materiales arqueofaunísticos y restos óseos humanos. Se recuperaron 7 puntas de proyectil.

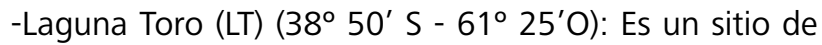
superficie ubicado en la laguna homónima (partido de Coronel Dorrego), distante a $12 \mathrm{~km}$ de la costa atlántica. Si bien el material recuperado se encuentra en procesamiento, se ha interpretado al sitio como un campamento de usos múltiples con entierros en el que se recolectaron artefactos líticos, tiestos cerámicos y restos óseos humanos, datados en $2369 \pm 52$ años AP (Scabuzzo et al., 2016). Fueron recuperadas 35 puntas.

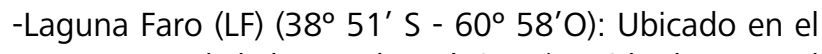
sector oeste de la laguna homónima (partido de Coronel Dorrego), es un sitio de superficie en el que fueron recuperados artefactos líticos, tiestos cerámicos y restos arqueofaunísticos. Datado entre ca. 4500 y 600 años AP., el sitio fue interpretado como un campamento de usos múltiples (Vecchi, Frontini y Bayón, 2019). Fueron recuperadas 9 puntas.

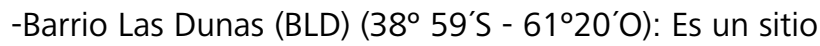
de superficie en las dunas costeras, con dataciones calibradas entre ca. 7700 a 7500 años AP e interpretado como un campamento de actividades múltiples (Bayón, Frontini y Vecchi, 2012; Frontini y Bayón, 2017b; Frontini, Bayón y Vecchi, 2021). En el sitio se recuperaron restos arqueofaunísticos y artefactos líticos, con la presencia de una punta de proyectil.

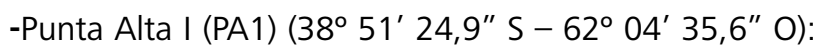
Ubicado en un sector del área periurbana de la localidad de Punta Alta, el sitio está constituido por una serie de acumulaciones de materiales líticos en superficie. Entre los artefactos formatizados se recuperaron 3 puntas de proyectil. La ausencia de materiales arqueofaunísticos no permitió la realización de dataciones radiocarbónicas para determinar la cronología del sitio.

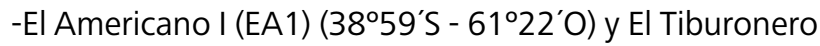
(ET) (38 $\left.58^{\prime} \mathrm{S}-61^{\circ} 26^{\prime} \mathrm{O}\right)$ : Son dos sitios de superficie ubicados en las dunas costeras (Conlazo, 1983). Se trata de sitios de características similares a otros analizados con anterioridad (i.e. Barrio Las Dunas), para los que se ha descripto la presencia de abundante material lítico, con presencia de 1 punta en El Americano I y 2 en El Tiburonero. En un sector cercano, dentro de la Reserva Provincial Pehuen-Có - Monte Hermoso (RPPCMH), fue hallada una punta aislada, considerada también en el análisis.

\section{Métodos y materiales}

Se analizó un total de 107 artefactos, que incluyen sólo aquellas puntas que pueden considerarse terminadas. De ellos, 92 fueron hallados en superficie (sitios Paso Mayor: $n=40$, Laguna Toro: $n=35$, Laguna Faro: $n=9$; Barrio Las Dunas: $n=1$, Punta Alta 1: $n=3$, El Tiburonero: $\mathrm{n}=2$, El Americano 1: $\mathrm{n}=1$; RPPCMH: $\mathrm{n}=1$ ). En tanto, en estratigrafía se hallaron 15 ejemplares: 4 en Paso Mayor, 7 en Paso Vanoli, y 4 en Puente de Fierro. Debido a que la mayor parte de este conjunto pertenece a sitios de superficie y su cronología absoluta es relativa, el análisis se centrará en evaluar los aspectos tecnomorfológicos, evitando, a excepción de aquellas piezas asociadas a dataciones en estratigrafía, vincular los posibles sistemas de armas a un periodo cronológico concreto.

Los estudios estadísticos se desarrollaron sobre 78 ejemplares, de los que 35 se encuentran enteros y 43 
están levemente fracturados lo que permitió inferir el largo y/o el ancho. Finalmente, 29 fragmentos no fueron considerados debido a que su grado de fragmentación no permitió determinar las variables mínimas requeridas.

Para el análisis se consideraron diferentes variables propuestas por Aschero $(1975,1983)$ y Nami (1984). Se registraron las materias primas, las dimensiones absolutas, las relaciones largo/ancho (tamaño y módulo longitudanchura), el espesor relativo, la forma base inicial, la sección transversal, la serie técnica, la forma de la base, el tratamiento técnico de la base, la conformación y la regularidad en bases y bordes, la forma de los lascados y la forma geométrica del contorno. En cuanto al peso sólo se consignó para las 35 piezas enteras. La determinación de las materias primas se realizó a nivel macroscópico, con el asesoramiento de la Dra. Cristina Frisicale (Dpto. Geología- UNS) y se comparó con la litoteca del Área de Arqueología (Dpto. Humanidades-UNS). Para la identificación de los diseños se siguieron las propuestas de Aschero (1988), Martínez (2007) y Martínez y colaboradores (2010).

Para la adscripción de las puntas a un sistema de armas particular se decidió integrar en el análisis estadístico tres variables métricas, como lo son el largo, el ancho y el espesor.

Con anterioridad, la identificación de diferentes sistemas de armas a partir del análisis tecno-morfológico de las puntas líticas fue recurrentemente planteado (Fenenga, 1953; Thomas, 1978; Shott, 1997; Hughes, 1998; Ratto, 1991 y 2003; entre otros). Algunas de estas propuestas serán utilizadas en forma comparativa para evaluar los resultados obtenidos a partir del análisis estadístico. Así, se considerará la propuesta de Fenenga (1953), quien utilizó la variable peso para diferenciar las puntas utilizadas en arco y flecha de las pertenecientes a lanzadera. Asimismo, se utilizará la propuesta de Thomas (1978), quien desarrolló diferentes fórmulas considerando las medidas máximas de largo, ancho y espesor de cada pieza (retomadas posteriormente por Shott en 1993 y 1997) para diferenciar los mismos sistemas de armas. Por último, los resultados se cotejarán con la propuesta de Hughes (1998), quien planteó fórmulas de cálculo a partir de la masa, el área de sección transversal y el perímetro de cada pieza, lo que le permitió identificar un mayor número de sistemas de armas: arco y flecha, dardos emplumados, dardos sin plumas, lanzas arrojadizas y lanzas de mano.
Para el análisis de las piezas se recurrió a tres métodos estadísticos: Coeficiente de Correlación de Pearson, Gráfico multivariado Biplot y Anova. El coeficiente de correlación de Pearson es una medida de asociación entre variables por el cual se mide el grado de relación lineal entre las variables. Con valores que oscilan entre -1 y 1 , aquellos muy cercanos a -1 y a 1 indican relación lineal, en tanto que los cercanos a cero indican que no la hay.

Para categorizar las piezas se recurrió al Biplot, un gráfico multivariado que permite visualizar las posiciones de las unidades muestrales con respecto a las otra y la importancia relativa de las variables en las posiciones de las mencionadas unidades. Por último, para comparar los valores medios de las variables en estudio dentro de cada grupo se utilizó el Análisis de Varianza (ANOVA) cuando cumplían los supuestos de la prueba y cuando alguno de los supuestos no se cumplió se recurrió a la prueba de comparación de medias no paramétrico KrusKal-Wallis.

\section{Resultados}

\section{Análisis estadístico}

Se realizó un análisis descriptivo de 78 piezas (Tabla 1) para cada una de las variables métricas (longitud, ancho y espesor). Puede observarse para todas las variables una gran dispersión (coeficiente de variación superior al $10 \%)$. Este primer análisis se completó mediante gráficos de caja (Figura 2A). A través de los gráficos de caja puede observarse la existencia de un valor atípico para la variable longitud (una pieza con una longitud extremadamente superior al resto), mientras que para las variables ancho y espesor se observa asimetría a derecha, es decir, una concentración mayor de piezas con menor ancho y espesor.

Del análisis estadístico descriptivo se concluye que las piezas son heterogéneas respecto a las variables en estudio. Para determinar si es posible realizar una segmentación de las mismas por grupos, con características métricas similares, se realizó un análisis estadístico multivariado con las variables en simultáneo.

En la matriz de correlación/coeficientes (Tabla 2), del análisis de componentes principales puede observarse que las variables Ancho y Espesor son las variables de mayor correlación $(0,83)$ y, en menor medida, que

Tabla 1: Síntesis de las variables métricas.

Table 1: Synthesis of the metric variables.

\begin{tabular}{|c|c|c|c|c|c|}
\hline Variable & Media & Desvío estándar & Coeficiente de variación & Mínimo & Máximo \\
\hline Longitud & 30,29 & 9,69 & 32 & 12,54 & 60,44 \\
\hline Ancho & 18,35 & 5,22 & 28,46 & 10,23 & 29,63 \\
\hline Espesor & 4,75 & 1,78 & 37,46 & 2,22 & 8,68 \\
\hline
\end{tabular}




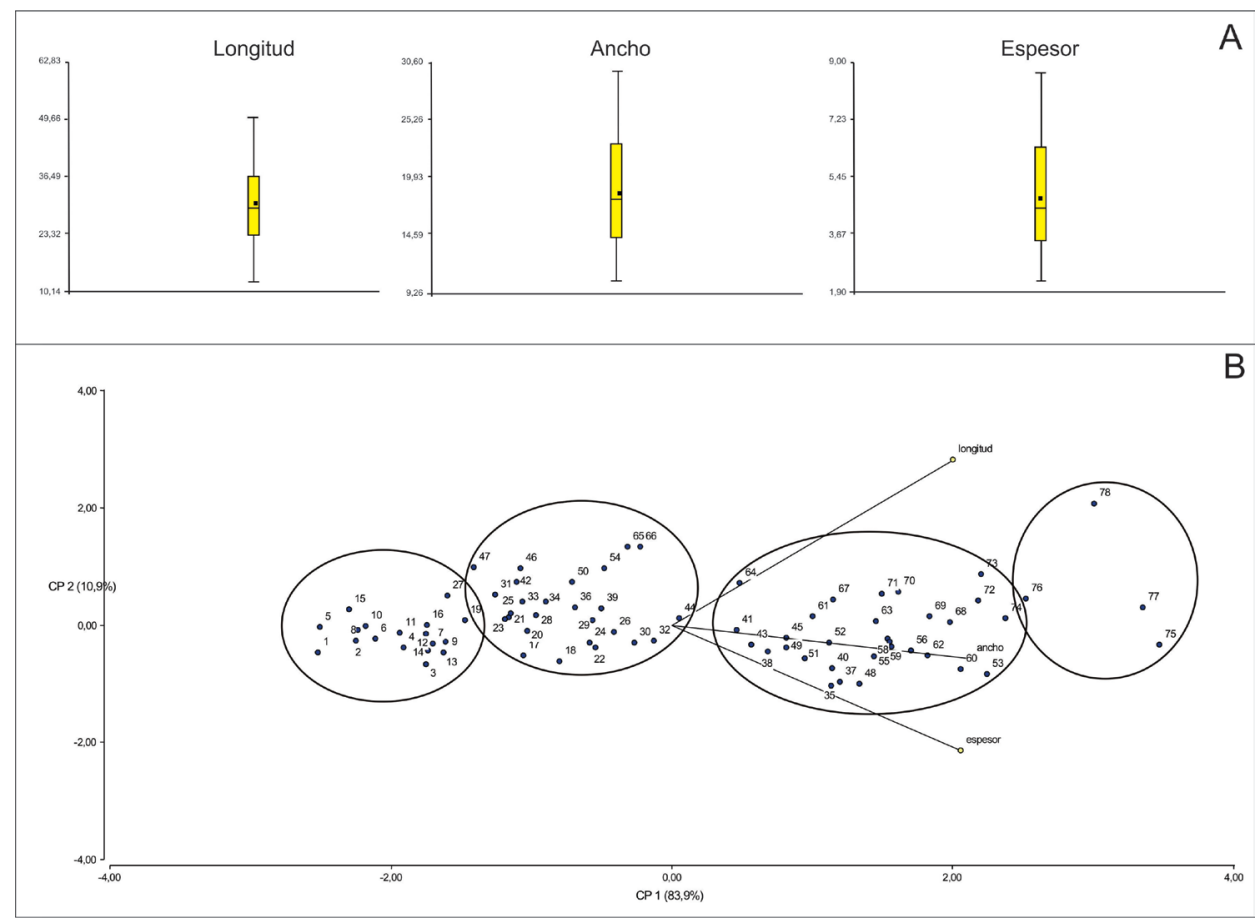

Figura 2: A: Gráficos de caja de variables longitud, ancho y espesor de las puntas de proyectil analizadas; B: Gráfico Biplot de las puntas de proyectil analizadas.

Figure 2: A: Box plots of variables length, width and

B thickness of the projectile points analyzed; B: Biplot box of the projectile points analyzed.

existe correlación entre las variables Longitud y Ancho (coeficiente de 0,77$)$ y Longitud y Espesor $(0,68)$.

Del gráfico Biplot (Figura 2B) puede observarse que las piezas se agrupan en cuatro categorías: Grupo Estadístico 1 (GE 1), conformado por 16 piezas pequeñas, más homogéneas en cuanto a su morfometría, con menor longitud, ancho y espesor; Grupo Estadístico 2 (GE 2), de 28 piezas medianas, con mayor longitud, más dispersas en cuanto al ancho y homogéneas respecto al espesor, y Grupo Estadístico 3 (GE 3) con 31 piezas grandes, de mayor longitud, ancho y espesor. Finalmente, se observa un cuarto grupo, Grupo Estadístico 4 (GE 4), conformado por 3 piezas con mayor longitud, ancho y espesor; muy heterogéneas entre sí con respecto a la variable espesor. En Tabla 3 se presenta un análisis descriptivo para cada uno de estos grupos, en el que puede observarse cómo, al agrupar las piezas, los coeficientes de variabilidad disminuyeron para cada una de las variables. Por ejemplo, para la variable ancho, los 4 grupos son homogéneos, presentando un coeficiente de variabilidad del $10 \%$.

Para determinar si los grupos presentan diferencias estadísticamente significativas para las variables métricas en estudio, se realizaron pruebas de comparación de medias, paramétricas o no paramétricas, según se cumpla o no el requisito de homocedasticidad. El GE 4 se descarta de este análisis debido a que se compone de sólo 3 piezas.

Dado que la prueba ANOVA (prueba paramétrica de igualdad de medias) es robusta ante la falta de normalidad sólo se verificó el supuesto de homocedasticidad (prueba de igualdad de varianzas) mediante el test de Levene. Para las variables longitud y espesor, esta prueba arrojó un valor $p<0,10$, por tanto, se rechazó el supuesto de homocedasticidad, no se pudo realizar el ANOVA y se recurrió a la prueba no paramétrica de Kruskal-Wallis.

Mientras que, para la variable ancho, la homocedasticidad no se rechazó (valor $p>0,10$ ) por lo que se realizó el ANOVA tradicional. Estas pruebas (paramétricas y no paramétricas) resultaron altamente significativas (valor $p<0,01)$, lo que permite concluir que para cada variable al menos uno de los grupos difiere de los demás. Posteriormente, se realizó la prueba T3 de Dunnet de comparaciones múltiples, para cada variable, concluyendo que todas las medias difieren entre sí (valor $p<0,01$ ). Es decir que los tres grupos presentan diferencias estadísticamente significativas entre los mismos.

\section{Análisis tecno-tipológico}

El conjunto presenta el predominio de puntas apedunculadas con limbos triangulares $(n=77)$, mientras que un solo ejemplar tiene pedúnculo. El

\begin{tabular}{|l|c|c|c|}
\hline & Longitud & Ancho & Espesor \\
\hline Longitud & 1,00 & & \\
\hline Ancho & 0,77 & 1,00 & \\
\hline Espesor & 0,68 & 0,83 & 1,00 \\
\hline
\end{tabular}

Tabla 2: Análisis de componentes principales.

Table 2: Principal Component Analysis. 


\begin{tabular}{|l|r|r|r|r|r|r|r|r|r|r|r|r|r|r|r|r|r|}
\cline { 2 - 13 } \multicolumn{1}{c|}{} & \multicolumn{4}{c|}{ Longitud (mm) } & \multicolumn{3}{c|}{ Ancho (mm) } & \multicolumn{3}{c|}{ Espesor (mm) } & \multicolumn{3}{c|}{ Peso (g) } \\
\hline GE & 1 & 2 & 3 & 4 & 1 & 2 & 3 & 4 & 1 & 2 & 3 & 4 & 1 & 2 & 3 & 4 \\
\hline Media & 17,7 & 28,0 & 36,7 & 52,4 & 12,4 & 15,6 & 22,8 & 29,3 & 3,0 & 3,6 & 6,5 & 7,1 & - & - & - & - \\
\hline Des. & 2,2 & 5,0 & 5,7 & 7,2 & 1,6 & 2,1 & 2,4 & 0,3 & 0,5 & 0,7 & 1,0 & 1,9 & - & - & - & - \\
\hline CV & 0,1 & 0,2 & 0,2 & 0,1 & 0,1 & 0,1 & 0,1 & 0,01 & 0,2 & 0,2 & 0,1 & 0,3 & - & - & - & - \\
\hline Mín. & 12,5 & 21,2 & 28,3 & 46,6 & 10,2 & 10,4 & 18,0 & 29,0 & 2,2 & 2,6 & 4,4 & 4,9 & 1 & 1 & 3 & 9 \\
\hline Máx. & 20,8 & 40,1 & 47,7 & 60,4 & 15,2 & 19,8 & 29,0 & 29,6 & 4,0 & 5,0 & 8,0 & 8,7 & $<1$ & 2 & 8 & 11 \\
\hline
\end{tabular}

Tabla 3: Análisis descriptivos de los grupos estadísticos. Referencia: GE: Grupo estadístico; Med.: Média; Des.: Desvío; CV.: Coeficiente de variación; Mín: Mínimo; Máx.: Máximo.

Table 3: Descriptive analysis of the statistical groups. Reference: GE: Statistical group; Med. : Medium; Des.: Deflection; CV .: Coefficient of variation; Min: Minimum; Max .: Maximum.

análisis tecno-tipológico se realizó considerando los grupos estadísticos. Los GE 1 y 2 tienen características tecnológicas semejantes. Presentan una reducción bifacial cuidada, con retoques regulares, de tipo parcialmente extendido/extendido realizados por presión. Predominan las bases adelgazadas mediante retoques. Las secciones transversales son biconvexas asimétricas o simétricas (GE 1: 53\%; GE 2: 43\%) y, en menor proporción, planoconvexas que retienen la forma de la lasca (GE 1: 21\%; GE 2: 26\%). Como formas base (FB) iniciales se usaron lascas (remanentes de cara ventral o dorsal) o formas base indiferenciadas ya que el retoque bifacial no permitió su identificación. En la conformación y regularidad del filo predominan los normal regular en el GE 1 (74\%) y los normales irregulares en el GE 2 (65\%). En cuanto a los tamaños, en el GE1 todas las piezas son pequeñas, con módulos longitud-anchura laminar normal y mediano alargado. En el GE2 predomina el tamaño mediano pequeño (83\%) seguido por el pequeño (17\%), con módulos de longitud-anchura laminar normal, laminar angosto y mediano alargado. El espesor relativo más frecuente es el medio (GE 1: 68\%; GE 2: 74\%), seguido por el muy delgado (GE 1: 21\%; GE 2: 26\%). En relación con el peso en el GE 1 los valores son menores a $1 \mathrm{gr}$, mientras que en el GE 2 entre 1 y 2,20 gr.

El GE 3 presenta piezas mayoritariamente mediano pequeñas (52\%), seguida de las de tamaño pequeño (48\%), con módulos de longitud-anchura laminares normales y mediano alargados. En tanto, en el espesor relativo predominan los medios (71\%). Las secciones transversales son menos regulares. Predomina la sección biconvexa asimétrica (68\%), seguida por las planoconvexas (19\%) y las biconvexas simétricas (16\%). El grupo estadístico se caracteriza por una mayor variabilidad tecno-tipológica y el uso frecuente de retoque con lascados parcialmente extendidos para la formatización de bordes. Es notoria la variedad de tratamientos en una misma pieza respecto al ancho y a la profundidad de los lascados. Las formas base fueron lascas, indiferenciadas y clastos tabulares. Se confeccionaron mediante retoque por presión y percusión. La conformación y regularidad del filo es, en la mayoría de los casos, normal irregular (55\%) y dentado regular o irregular (29\%). El tratamiento de las bases más frecuente fue el adelgazamiento por retoques mediante la combinación de lascados paralelos cortos y laminares. En algunos casos (como dos piezas correspondientes a la Localidad Arqueológica Paso Mayor: PM 63/232 y PM 63/41) la base no fue retocada y la delgadez de la lasca usada como forma base permitió el enmangue sin otras modificaciones. El peso en este grupo oscila entre 3 gr y 7,7 gr.

El GE 4 es minoritario en cuanto al número de puntas $(n=3)$, por lo que su análisis es limitado. Se trata de dos piezas apedunculadas y una pedunculada, formatizadas mediante el uso de retoque con lascados parcialmente extendidos y extendidos, con filos normales regulares $(n=2)$ e irregulares $(n=1)$. Dos de ellas presentan tamaños mediano grande, en tanto la restante es de tamaño grande. Con espesores muy delgados $(n=2)$ y medio $(n=1)$, sus secciones longitudinales muestran formas diferentes: biconvexa simétrica, biconvexa asimétrica y plano convexa. Los pesos de las piezas oscilan entre los 5 y $11 \mathrm{gr}$. Debemos destacar que la pieza pedunculada (recuperada en superficie en la Reserva Provincial Pehuen-Có - Monte Hermoso) es la única con estas características presente en el total de puntas relevadas, y posee un diseño afín a las halladas en contextos patagónicos (Cardillo y Alberti, 2015; Banegas et al., 2014; entre otros)

El mantenimiento está presente en los tres grupos con frecuencias variables y principalmente afecta el tercio superior. El porcentaje de piezas mantenidas es en el GE1 $(n=16)$ del $44 \%$, en el GE2 $(n=28)$ el $11 \%$ y en el GE3 ( $n=31)$ del 45\%, no habiendo sido identificado en el GE 4.

En relación con las materias primas en GE 1 predominan los sílices $(62,50 \%)$, seguidos por las rocas basálticas $(18,75 \%)$, las OGSB $(12,50 \%)$ y una roca no determinada $(6,25 \%)$. En el GE2 prevalecen los sílices (53.57\%), seguidos por rocas basálticas $(28,57 \%)$, las OGSB $(7,14 \%)$, y finalmente el chert silíceo verde, la riolita y la subarcosa $(3,57 \%$ respectivamente). En el grupo estadístico GE3 las rocas basálticas representan el 32,25\%; los sílices, la subarcosa y el chert silíceo verde constituyen el $16,13 \%$ cada una; la riolita y las OGSB son el $6,45 \%$ cada una y hay un ejemplar de ftanita, de roca cuarcítica y de una roca ígnea indeterminada. En escasos ejemplares de los tres GE (5\%) se observa remanente de corteza que corresponde a la de los 


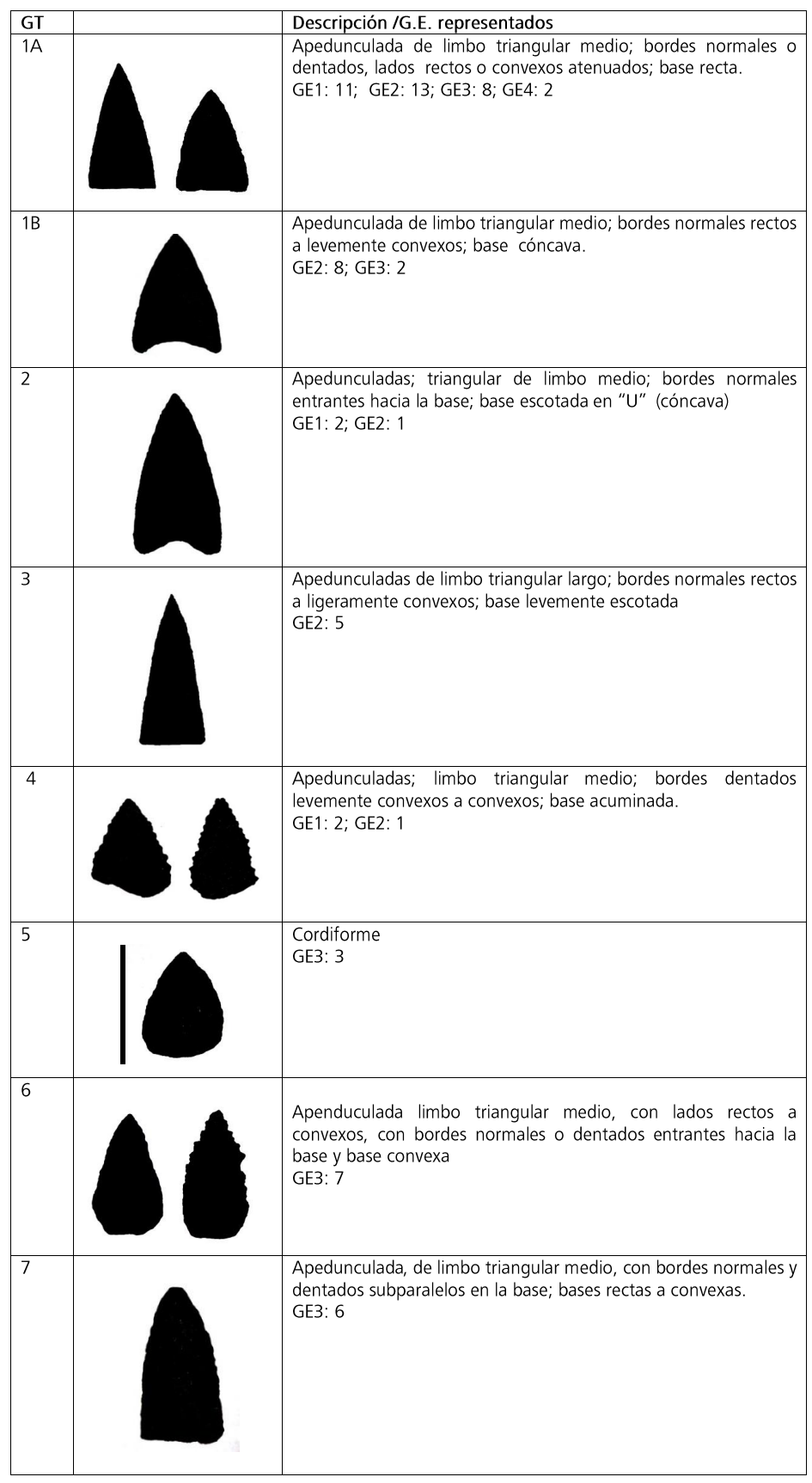

Tabla 4: Tipos morfológicos de puntas de proyectil y número de piezas representadas por grupo estadístico.

Table 4: Morphological types of projectile points and number of pieces represented by statistical group.

rodados costeros y fluviales (conformados en el primer grupo por basandesitas y sílices y, en el segundo, por rocas cuarcíticas). Por último, se reconocieron siete tipos morfológicos (Aschero 1988, Martínez et al. 2010) según la forma geométrica del contorno, de la base y de los bordes, los que se describen en la Tabla 4. Si bien predominan las puntas con lados rectos (o convexos atenuados), de bordes normales y base recta, se han registrado otras morfologías no descriptas anteriormente para el área bajo estudio, como piezas con bordes dentados y base acuminada o convexa, cordiformes, etc. Los tipos están presentes en los distintos grupos estadísticos en proporciones variables. Mientras que en el GE 1 predominan las puntas de limbo triangular medio de lados rectos y base recta, en el GE 2 están representadas, mayoritariamente, las puntas de limbo triangular mediano y largo de lados rectos, tanto de base recta como cóncava. Por último, es notorio que el GE3 es el que presenta mayor variabilidad morfológica, con presencia de 5 tipos morfológicos de los 7 identificados. 


\section{Discusión y conclusiones}

El primer aspecto a discutir es el referido a la cronología del conjunto de puntas. Se trata de un tema de difícil resolución porque sólo 15 de ellas fueron recuperadas en niveles estratigráficos datados. De éstas, solo 5 pudieron ser analizadas (halladas en los sitios Paso Vanoli y Puente de Fierro) y corresponden al Holoceno tardío y forman parte de los GE 1 y 2 . Los restantes 73 especímenes analizados provienen de superficie y fueron expuestos por erosión eólica. Es por eso que, si bien en varios de los sitios se cuentan con dataciones radiocarbónicas tanto para los niveles estratigráficos como para los materiales de superficie, solo es posible realizar inferencias generales y no concluyentes. El sitio Barrio Las Dunas (fechado en el Holoceno medio) presenta una única pieza correspondiente al GE 3. En el sitio Laguna Toro (datado en el Holoceno tardío), predominan las piezas de los GE 1 y 2 (7 y 11 piezas respectivamente), con 5 correspondientes al GE 3 y 1 al GE 4. En tanto, la Localidad arqueológica Paso Mayor y el sitio Laguna Faro presentan dataciones desde el Holoceno medio al tardío, y cuentan con piezas adscriptas a los cuatro grupos estadísticos.

Con respecto a las materias primas, se observó un uso preferencial de los sílices para confeccionar la mayoría de las piezas pequeñas y delgadas (GE 1 y GE 2). Las piezas de mayor tamaño (GE 3) se confeccionaron predominantemente en rocas basálticas pero usaron también riolita, subarcosa, chert silíceo verde y sílices. Las OGSB están presentes en bajas proporciones en los GE 1, 2 y 3. Consideramos que el abastecimiento de rocas fue predominantemente areal, ya que sílices y rocas basálticas se encuentran entre los rodados costeros del litoral atlántico del sector y las subarcosas están disponibles en los depósitos gravosos del río Sauce Grande. Otras rocas fueron trasladadas por distancias variadas. La riolita y el chert silíceo verde probablemente procedan de las Sierras Australes y áreas aledañas (ca. 100 km), mientras que las OGSB y la ftanita vienen de larga distancia (Sierras Septentrionales), a más de $300 \mathrm{~km}$.

En el conjunto analizado, no hemos observado bifaces ni preformas de etapas previas de adelgazamiento bifacial. La formatización de las puntas fue de reducción bifacial, partiendo de lascas de tamaño cercano al de las piezas terminadas. Un patrón de lascados más regular caracteriza a las piezas de los GE 1 y GE 2 observándose sólo en algunos escasos especímenes del GE 3. Esto permitió un acabado cuidadoso de las caras y una mayor simetría de las secciones. No obstante, especialmente en el GE 3, se observan tratamientos muy disímiles entre ambas caras de una misma pieza, y en algunos casos la forma base lasca apenas fue modificada por negativos cortos poco penetrantes. Esto también se refleja en una mayor asimetría de las secciones. Esta variabilidad del conjunto GE 3 le confiere una impronta de escasa estandarización.
El mantenimiento de ápices y bordes se presenta como una característica de importancia dentro del conjunto, lo que abona la propuesta hecha por diferentes autores sobre la modificación de las piezas para prolongar su uso (Escola, 2014; Hocsman et al., 2012; Valverde y Martucci, 2004; Vigna et al., 2014; entre otros). Dichas modificaciones se observaron especialmente en el sector del ápice. Sólo en pocos casos el mantenimiento afectó completamente la morfología de la pieza.

El manejo estadístico de los datos resultó útil para organizar el conjunto y su variabilidad en tamaños y diseños, lo que nos permitió reconocer tres grupos estadísticos relevantes desde un punto de vista arqueológico, aunque probablemente se trate de dos debido a las similitudes tecnológicas y tipológicas entre los GE 1 y GE 2. Podría plantearse, inicialmente, que las diferencias entre estos grupos estadísticos y el GE 3 estarían relacionadas con la presencia de diferentes sistemas de armas, correspondientes a arco y flecha los dos primeros y a lanzadera (dardo) el tercero. Si bien son minoritarias las piezas asignadas al GE 4, podría plantearse su uso en lanzas de mano (Churchill, 1993; Martínez, 2007; Ratto, 1991).

Los resultados obtenidos mediante el análisis estadístico y la adscripción de las diferentes puntas a un sistema de armas particular fueron cotejados con las propuestas analíticas planteadas por Fenenga (1953), Thomas (1978) y Hughes (1998). Se obtuvieron así una serie de valores (plasmados en la Tabla 5) que muestran una alta coincidencia en la determinación del sistema de armas asignado a cada punta, a excepción de un conjunto de puntas del GE 2, asignadas a arco y flecha y que en la propuesta presentada por Thomas (1978) son interpretadas como puntas de dardos. No obstante esta variación, consideramos que los datos obtenidos permiten reforzar la interpretación realizada a partir de la cual es posible proponer que los valores métricos consignados en la Tabla 3 fueron útiles para la asignación de diferentes sistemas de armas con cabezal lítico, en especial para los utilizados en la región pampeana.

Por otra parte, los tipos morfológicos reconocidos (Tabla 4) evidencian que, en la aparente homogeneidad del grupo tipológico puntas triangulares apedunculadas, se observan importantes variaciones en la manera de delinear los limbos y las bases. Algunos de los tipos morfológicos se repiten en los distintos grupos estadísticos de manera frecuente (por ejemplo 1a y $1 \mathrm{~b}$ - Tabla 4), lo que indica la preferencia por esa morfología.

En la comparación de las puntas del sudoeste bonaerense con las halladas en otras áreas de la provincia de Buenos Aires para el Holoceno medio y tardío podemos establecer similitudes y diferencias. Estos aspectos, observados en el conjunto analizado, incluyen cronología, materias primas, diseños básicos y características tecnológicas. 


\begin{tabular}{|c|c|c|c|c|c|c|c|c|c|c|c|}
\hline \begin{tabular}{r|}
$\mathrm{N}^{\circ} \mathrm{de}$ \\
Biplot
\end{tabular} & $\mathrm{N}^{\circ}$ de pieza & G. E. & \begin{tabular}{|l}
$\begin{array}{l}\text { Hughes } \\
(1998)\end{array}$ \\
\end{tabular} & \begin{tabular}{|l|} 
Fenenga \\
$(1953)$
\end{tabular} & \begin{tabular}{|l}
$\begin{array}{l}\text { Thomas } \\
(1978)\end{array}$ \\
\end{tabular} & \begin{tabular}{|l|}
$N^{\circ}$ de \\
Biplot \\
\end{tabular} & $\mathrm{N}^{\circ}$ de pieza & G. E. & \begin{tabular}{|l} 
Hughes \\
(1998)
\end{tabular} & \begin{tabular}{|l|} 
Fenenga \\
$(1953)$
\end{tabular} & $\begin{array}{l}\text { Thomas } \\
\text { (1978) }\end{array}$ \\
\hline 1 & PM I-1 63/1058 & 1 & Flecha & Flecha & Flecha & 40 & PM II-2 63/601 & 3 & Dardo & - & Dardo \\
\hline 2 & PM I-1 63/1020 & 1 & Flecha & - & Flecha & 41 & PM I-2 63/41 & 3 & Dardo & - & Dardo \\
\hline 3 & LT8 & 1 & Flecha & Flecha & Flecha & 42 & PM I-1 63/1054 & 2 & Flecha & - & Flecha \\
\hline 4 & LT15 & 1 & Flecha & - & Flecha & 43 & LT5 & 3 & Dardo & - & Dardo \\
\hline 5 & LT20 & 1 & Flecha & Flecha & Flecha & 44 & LT26 & 2 & Flecha & - & Dardo \\
\hline 6 & PM I-1 63/1063 & 1 & Flecha & Flecha & Flecha & 45 & PM I-2 63/232 & 3 & Dardo & - & Dardo \\
\hline 7 & LT18 & 1 & Flecha & Flecha & Flecha & 46 & LT11 & 2 & Flecha & Flecha & Flecha \\
\hline 8 & PM I-1 63/1146 & 1 & Flecha & - & Flecha & 47 & PM I-1 63/1430 & 1 & Flecha & Flecha & Flecha \\
\hline 9 & PM I-1 63/1065 & 1 & Flecha & Flecha & Flecha & 48 & LFC 82 & 3 & Dardo & Dardo & Dardo \\
\hline 10 & PV 81-71 & 1 & Flecha & - & Flecha & 49 & LT3 & 3 & Dardo & - & Dardo \\
\hline 11 & LT21 & 1 & Flecha & Flecha & Flecha & 50 & PM I-1 63/1059 & 2 & Flecha & Flecha & Flecha \\
\hline 12 & PF 149 & 1 & Flecha & Flecha & Flecha & 51 & LF s/n & 3 & Flecha & Flecha & Dardo \\
\hline 13 & PF 653 & 1 & Flecha & Flecha & Flecha & 52 & PM I-2 63/11 & 3 & Dardo & Dardo & Dardo \\
\hline 14 & PM I-2 63/12 & 1 & Flecha & - & Flecha & 53 & ET 2 & 3 & Dardo & - & Dardo \\
\hline 15 & PM I-1 63/1527 & 1 & Flecha & - & Flecha & 54 & PA I 3_2016 & 2 & Flecha & Flecha & Dardo \\
\hline 16 & LT14 & 1 & Flecha & - & Flecha & 55 & ET 1 & 3 & Dardo & Flecha & Dardo \\
\hline 17 & LT30 & 2 & Flecha & - & Flecha & 56 & BLD 781 & 3 & Dardo & Dardo & Dardo \\
\hline 18 & PM I-1 63/1064 & 2 & Flecha & Flecha & Dardo & 57 & PM I-2 63/10 & 3 & Dardo & Dardo & Dardo \\
\hline 19 & PM I-1 63/1071 & 1 & Flecha & - & Flecha & 58 & LF s/n & 3 & Dardo & Dardo & Dardo \\
\hline 20 & PM I-1 63/1072 & 2 & Flecha & - & Dardo & 59 & PM I-2 63/9 & 3 & Dardo & Dardo & Dardo \\
\hline 21 & LT34 & 2 & Flecha & - & Dardo & 60 & LFC 85 & 3 & Dardo & - & Dardo \\
\hline 22 & LT4 & 2 & Flecha & Flecha & Dardo & 61 & PM I-2 63/25 & 3 & Flecha & - & Dardo \\
\hline 23 & LT33 & 2 & Flecha & - & Flecha & 62 & PAI 2_2016 & 3 & Dardo & - & Dardo \\
\hline 24 & LF s/n & 2 & Flecha & - & Dardo & 63 & LF s/n & 3 & Dardo & - & Dardo \\
\hline 25 & PV 117_71 & 2 & Flecha & - & Dardo & 64 & LT35 & 3 & Flecha & Flecha & Dardo \\
\hline 26 & PM I-2 63/13 & 2 & Flecha & - & Dardo & 65 & LT25 & 2 & Flecha & - & Flecha \\
\hline 27 & LT1 & 1 & Flecha & Flecha & Flecha & 66 & $\mathrm{EA} / 3$ & 2 & Flecha & - & Flecha \\
\hline 28 & LT7 & 2 & Flecha & - & Dardo & 67 & LT19 & 3 & Dardo & - & Dardo \\
\hline 29 & PM I-1 63/1069 & 2 & Flecha & - & Dardo & 68 & PM I-2 63/17 & 3 & Dardo & Dardo & Dardo \\
\hline 30 & LFC 89 & 2 & Flecha & Flecha & Dardo & 69 & PM I-1 63/26 & 3 & Dardo & Dardo & Dardo \\
\hline 31 & PM I-1 63/1070 & 2 & Flecha & - & Flecha & 70 & LT2 & 3 & Dardo & Dardo & Dardo \\
\hline 32 & LT23 & 2 & Flecha & - & Dardo & 71 & PM I-2 63/16 & 3 & Dardo & - & Dardo \\
\hline 33 & LT28 & 2 & Flecha & - & Flecha & 72 & PM I-2 63/27 & 3 & Dardo & Dardo & Dardo \\
\hline 34 & LT22 & 2 & Flecha & - & Dardo & 73 & LFC 73 & 3 & \begin{tabular}{|l|} 
Lanza \\
de \\
mano \\
\end{tabular} & - & Dardo \\
\hline 35 & PAI1_2016 & 3 & Dardo & - & Dardo & 74 & PM I-2 63/22 & 3 & Dardo & Dardo & Dardo \\
\hline 36 & LT17 & 2 & Flecha & - & Dardo & 75 & RP-MH & 4 & \begin{tabular}{|l|} 
Lanza \\
de \\
mano \\
\end{tabular} & Dardo & Dardo \\
\hline 37 & PM I-1 63/137 & 3 & Dardo & - & Dardo & 76 & PM I-2 63/23 & 3 & \begin{tabular}{|l|} 
Lanza \\
voladora \\
\end{tabular} & Dardo & Dardo \\
\hline 38 & PM I-1 63/105 & 3 & Dardo & - & Dardo & 77 & PM I-2 63/19 & 4 & \begin{tabular}{|l|} 
Lanza \\
de \\
mano \\
\end{tabular} & Dardo & Dardo \\
\hline 39 & PV 5-72-3 & 2 & Flecha & - & Dardo & 78 & LT10 & 4 & \begin{tabular}{|l} 
Lanza \\
de \\
mano
\end{tabular} & - & Dardo \\
\hline
\end{tabular}

Tabla 5: Análisis comparativo de las propuestas de asignación de las puntas analizadas a diferentes sistemas de armas.

Table 5: Comparative analysis of the proposals for assigning the points analyzed to different weapon systems.

Para el área de la Depresión del Río Salado, se han recuperado 15 puntas en diferentes sitios (La Guillerma 1, La Guillerma Ñandú, San Ramón 5, San Ramón 7 y Techo Colorado), todos ubicados cronológicamente en el Holoceno tardío (Vigna et al., 2014; González et al. 2021). A excepción de una pieza de tamaño mediano grande (asignada a lanzadera), todas las piezas relevadas presentan tamaño pequeño y fueron asignadas al uso de arco y flecha. Las puntas están confeccionadas a partir de lascas como formas base, mayoritariamente en OGSB $y$, en bajas proporciones, en ftanita y dolomía silicificada. Entre los diseños básicos reconocidos, se han identificados piezas que muestran semejanzas con tipos morfológicos 1B, 2 y 3 presentados aquí.
En las Sierras de Tandilia, se han recuperado puntas en un importante número de sitios datados en el Holoceno tardío, como Cueva El Abra, Lobería 1, Cerro La China (Flegenheimer, 1986-1987; Valverde y Martucci, 2004; Mazzanti 2006; entre otros). En su mayor parte se trata de puntas triangulares apedunculadas pequeñas y medianas, con presencia de puntas lanceoladas medianas, a partir de lo cual se postuló el uso de arco y flecha junto con lanzadera o lanza. Las piezas fueron confeccionadas mediante formatización bifacial a partir de lascas como formas base. Con tipos morfológicos predominantemente 1 A y 3 , con presencia de piezas del tipo 7 en el caso de las puntas medianas. En su mayor parte están confeccionadas en ortocuarcitas y, en menor proporción, rocas cuarcíticas, 
basandesita, sílice y cuarzo.

En el área Interserrana, los sitios son numerosos y solo se ha considerado una proporción pequeña de los mismos (como Arroyo Seco 2, Hangar, Calera, Empalme Querandíes). Para el Holoceno medio, las puntas recuperadas en Arroyo Seco 2 son apedunculadas, de limbo triangular mediano y largo, confeccionadas en cuarcitas de grano fino y medio y sílice a partir de lascas como forma base (Escola, 2014), observando piezas afines a los grupos tipológicos 1A, 5 y 7 . En el Holoceno tardío la presencia de puntas de proyectil es generalizada y recurrente, en sitios en estratigrafía como contextos de superficie. En sitios como Arroyo Seco 2, Hangar, Calera y Empalme Querandíes y Quequén Saldo 1, las puntas están representadas por piezas de tamaño pequeño, mediano pequeño y mediano, las que fueron asignadas para el uso de arco y flecha y lanzadera (Kaufmann et al., 2021). Formatizadas a partir de lascas, las puntas presentan mayoritariamente los tipos morfológicos $1 \mathrm{~A}$ y $1 \mathrm{~B}$, con presencia también de los tipos 2 y 7 . Como materias primas, se utilizaron ortocuarcitas del grupo Sierras Bayas, chert, sílice, caliza, riolita, calcedonia y basandesita (Bonomo, 2004; Escola, 2014; Barros et al., 2018; Kaufmann et al., 2021).

Por otra parte, para el área del Centro-oeste Pampeano, las puntas recuperadas en contextos de superficie (La Susana 1, Huencú Nazar) o en niveles estratigráficos asignados al Holoceno tardío (Cabeza de Buey), son apedunculadas de tamaño medianas, mediano pequeñas y pequeñas. Confeccionadas en riolita, ftanita, limolita silicificada y ortocuarcitas, se reconocieron los tipos morfológicos 1A y 3 (Messineo y Scheifler, 2016; Scheifler, 2019).

Por último, en el curso inferior del río Colorado se cuenta con puntas asociadas a contextos del Holoceno medio (La Modesta) y del tardío (Campo Monaldi 1, Campo Monaldi 2 y Zoko Andi 1). Las piezas asignadas al Holoceno medio son de tamaño mediano pequeño y mediano grande, confeccionadas en basandesita, sílice sedimentario, calcedonia y rocas silíceas. Confeccionadas a partir de lascas como forma base, se identificaron los tipos morfológicos 1A y 6. En tanto, para el Holoceno tardío, las puntas son de tamaño pequeño, mediano pequeño, mediano y mediano grande, confeccionadas preferentemente en rocas silíceas, aunque también en calcedonia, sílice sedimentario, riolita, basandesita y xilópalo. Los tipos morfológicos identificados incluyen 1A, 1B, 2, 3 y 5 (Santos Valero, 2017).

En términos generales, se observan algunos elementos comunes en las puntas de proyectil de las diferentes áreas de la región pampeana. Por un lado, en la selección de rocas predomina el uso de ortocuarcitas, calcedonias (ftanitas) junto con sílices y basandesitas, éstas últimas mayormente en áreas con presencia de rodados de este tipo de rocas, principalmente en el sector costero del área interserrana, el sudoeste o el curso inferior del río Colorado. Por otra parte, predomina en todas las áreas la formatización de las puntas mediante la reducción bifacial, partiendo de lascas como forma base. Asimismo, se observan tipos morfológicos que se reiteran con mayor o menor proporción en las distintas áreas. Si bien predominan las puntas apedunculadas de limbo triangular medio y lados rectos o convexos atenuados, tanto de base recta como cóncava (GT $1 \mathrm{~A}$ y $1 \mathrm{~B}$ ), es reiterado también el uso de aquellas de limbo medio con bordes normales entrantes hacia la base de forma cóncava (GT 2), las de limbo triangular largo (GT 3), y las de limbo triangular medio con bordes subparalelos en la base (GT 7), estas últimas especialmente en puntas de tamaño mediano. Algunos grupos tipológicos, como las de limbo triangular medio de base acuminada (GT 4), las cordiformes (GT 5) y las de limbo triangular medio con bordes entrantes a la base de forma convexa (GT 6), parecen estar limitadas al sudoeste y al curso inferior del río Colorado.

Más allá de algunas diferencias areales, estas regularidades observadas en las formas de diseño y las modalidades de manufactura en una escala espacial amplia permiten inferir la existencia de información técnica compartida y transmitida, es decir, de una herencia técnica común a diferentes grupos dentro de la región. Ese "modo de hacer" recurrente se observa más allá de las propiedades de las materias primas utilizadas, la calidad en la ejecución de los artesanos o las elecciones técnicas individuales (Boëda, 1994; Dobres y Hofmann, 1994; Lemonnier, 1992; Pellegrin, 1991).

\section{Agradecimientos}

Les autores agradecen a las Dras. P. Escola, R. Frontini y C. Frisicale; al Museo y Archivo Histórico de Bahía Blanca; Museo de Ciencias Naturales "Vidente Di Martino", Monte Hermoso; Museo de Ciencias Naturales de Punta Alta; Reserva Provincial Geológica, Paleontológica y Arqueológica Pehuen co-Monte Hermoso; Museo Regional "Dr. Carlos Funes Derieul", Coronel Dorrego; Sres. Horacio Diomedi, Facundo Cabrera Brizuela y Rubén Cisneros; Subsidios: PICT BID 2013/2175, PICT BID 2015/0272; PIP 112-201301-00632CO; SECYT-UNS 24/I222.

\section{Bibliografía}

Aschero, C. A. (1975). Ensayo para una clasificación morfológica de artefactos líticos aplicada a estudios tipológicos comparativos. Buenos Aires, Argentina, Informe al CONICET, Ms.

Aschero, C. A. (1983). Ensayo para una clasificación morfológica de artefactos líticos aplicada a estudios tipológicos comparativos. Revisión. Buenos Aires, Argentina, Informe al CONICET, Ms. 
Aschero, C. A. (1988). De punta a punta: Producción, mantenimiento y diseño en puntas de proyectil precerámicas de la Puna argentina. En Actas del IX Congreso Nacional de Arqueología Argentina (pp. 219229), Buenos Aires, Argentina.

Aschero, C. y Martínez, J. (2001). Técnicas de caza en Antofagasta de la Sierra, Puna meridional argentina. Relaciones de la Sociedad Argentina de Antropología, XXVI, 215-241.

Austral A. G. (1968). Los hallazgos arqueológicos de Paso Mayor II. Cuadernos del Sur, 8-9, 1-32.

Austral, A. y García Cano, J. (1999). Un caso de arqueología en lagunas pampeanas. El sitio SA 29 LE, Las Encadenadas en el Partido de Saavedra, Provincia de Buenos Aires. Aplicación de técnicas de prospección subacuática. En Actas XII Congreso Nacional de Arqueología Argentina III (pp. 87-94), La Plata, Argentina: Editorial de la UNLP.

Austral, A. y Pérez Amat, M. E. (1985). El yacimiento-sitio Paso Vanoli (Partido de Bahía Blanca). Trabajo presentado en el VII Congreso Nacional de Arqueología Argentina, Concordia, Argentina, Ms.

Banegas, A., Gómez Otero, J., Goye, S. y Ratto, N. (2014). Cabezales líticos del Holoceno tardío en Patagonia Meridional: Diseños y asignación funcional. Magallania, $42(2), 155-174$.

Barros, M. P., Heider, G., Álvarez M. C., Kaufmann, C. y JBellinzoni, J. (2018). First results of the huntergatherer weapon system studies in the middle basin of the Salado creek (Pampas Region, Argentina). Journal of Lithic Studies, 5 (2), 1-23. http://doi.org/10.2218/ jls. 2785 .

Barros, P. y Messineo, P. (2004). Identificación y aprovisionamiento de chert o ftanita en la cuenca superior del Arroyo Tapalque. Estudios Atacameños, 28, 87-103.

Bayón, C. y Frontini, R. (2016). Actividades domésticas en los humedales del sudoeste bonaerense. En Actas del XIX Congreso Nacional de Arqueología Argentina. Serie Monográfica y Didáctica 54 (pp. 604-606), San Miguel de Tucumán, Argentina: Facultad de Ciencias Naturales e Instituto Miguel Lillo de la Universidad Nacional de Tucumán.

Bayón, C., Frontini, R. y Vecchi, R. (2012). Middle Holocene settlements on coastal dunes, southwest Buenos Aires Province, Argentina. Quaternary International, 256, 54-61.

Bayón, C., Pupio, A., Frontini, R., Vecchi, R. y Scabuzzo,
C. (2010). Localidad arqueológica Paso Mayor: nuevos estudios 40 años después. Intersecciones en Antropología, $11,115-128$.

Bayón, C., Vecchi, R., y Pupio, A. (2010). Los recursos líticos en el Sitio Y1SI de la localidad arqueológica Paso Mayor. En La Arqueometría en Argentina y Latinoamérica (pp. 135-140). Facultad de Filosofía y Humanidades de la Universidad Nacional de Córdoba, Córdoba.

Bayón, C. y Zavala, C. (1997). Coastal sites in southern Buenos Aires: A review of "Piedras Quebradas". Quaternary of South America and Antarctic Peninsula, 10 (1994), 229-252.

Berón, M. y Politis, G. (1997). Arqueología pampeana en la década de los `90. Estado de las investigaciones y perspectivas. En M. Berón y G. Politis (Comp.), Arqueología pampeana en la década de los '90 (pp.732), Olavarría, Argentina: Museo de Historia Natural de San Rafael (Mendoza)-INCUAPA.

Böeda, E. (1994). Le concept Levallois: Variabilité des methods. París, Francia: CNRS, Monographie du CRA 9.

Bonomo, M. (2004). Ocupaciones humanas en el litoral marítimo pampeano: un enfoque arqueológico. Tesis Doctoral inédita. La Plata: Facultad de Ciencias Naturales y Museo, Universidad Nacional de La Plata.

Bonomo, M. y Prates, L. (2014). La explotación de depósitos secundarios de rodados en el curso medio del río Negro y el litoral marítimo pampeano. En P. Escola y S. Hocsman (Eds.), Artefactos Líticos, Movilidad y Funcionalidad de Sitios en Sudamérica. Problemas y Perspectivas (pp. 77-92), Oxford, Gran Bretaña: British Archaeological Reports (BAR) International Series.

Bróndolo, M., Campos, M., Zinger, A., del Pozo, O. y Lorda, M. A. (1994). Geografía de Bahía Blanca. Bahía Blanca, Argentina: Editorial Encestando.

Cardillo, M. y Alberti, J. (2015). The evolution of projectile points and technical systems: a case from Northern Patagonian coast (Argentina). Journal of Archaeological Science: Reports, 2, 612-623.

Churchill, S. (1993). Weapon Technology, Prey Size Selection, and Hunting Methods in Modern HunterGatherers: Implications for Hunting in the Palaeolothic and Mesolothic. En G. L. Peterkin, H. M. Bricker y P. Mellars (Eds.), Hunting and Animal Exploitation in the Later Palaeolithic and Mesolithic of Eurasia (pp. 11-24), Arlington, Estados Unidos: Archaeological Papers of the American Anthropological Association. 
Colombo, M. (2013). Los cazadores recolectores pampeanos y sus rocas. La obtención de materias primas líticas vista desde las canteras arqueológicas del centro de Tandilia. Tesis Doctoral inédita. La Plata: Facultad de Ciencias Naturales y Museo, Universidad Nacional de La Plata.

Conlazo D. (1983). Resultados de una prospección en la zona medanosa de la costa sur de la Provincia de Buenos Aires. ADEHA, 1 (1), 32-51.

Dobres, M. y Hoffman, Ch. (1994). Social Agency and the Dynamics of Prehistoric Technology. Journal of Archaeological. Method and Theory, 1 (3), 211258.

Escola, P. (2014). Proyectiles líticos en contexto en Arroyo Seco 2: algo más que una tecnología para la caza. En G. G. Politis, M. A. Gutiérrez y C. Scabuzzo (Eds.), Estado actual de las investigaciones en el sitio arqueológico Arroyo Seco 2 (Partido de Tres Arroyos, provincia de Buenos Aires, Argentina) (pp. 313-327), Tandil, Argentina: INCUAPA-CONICET-UNICEN.

Fenenga, F. (1953). The weights of chipped stone points: A clue to their functions. Southwestern Journal of Anthropology, 9, 309-323.

Flegenheimer, N. (1986-1987). Excavaciones en el sitio 3 de la Localidad Cerro La China (provincial de Buenos Aires). Relaciones de la Sociedad Argentina de Antropología, XVII (1), 7-28.

Flegenheimer, N., Kain, S., Zarate, M. y Barna, A. (1996). Aprovisionamiento de cuarcitas en Tandilla, las canteras del arroyo Diamante. Arqueología, 6, 117-141.

Flegenheimer, N., Martínez, J. G. y Colombo, M. (2010). Una Experiencia de Lanzamiento de puntas cola de pescado. En M. Berón, L. Luna, M. Bonomo, C. Montalvo, C. Aranda y M. Carrera Aizpitarte (Eds.), Mamül Mapu: Pasado y Presente desde la Arqueología Pampeana (pp. 215-236), Buenos Aires, Argentina: Editorial Libros del Espinillo.

Frontini, R. y Bayón, C. (2015). Consumo de recursos animales de porte menor durante el Holoceno tardío en el sudoeste de la provincia de Buenos Aires (Argentina). Archaeofauna, 24, 271-293.

Frontini, R. y Bayón, C. (2017a). El registro malacológico del sitio Puente de Fierro (provincia de Buenos Aires, Argentina). Arqueología, 23 (3), 91-106.

Frontini, R. y Bayón, C. (2017b). Use of marine resources (fauna and tool stones) in the southwest of Buenos Aires Province (Argentina) during the Middle and Late Holocene. En M. Mondini, A. Sebastián Muñóz y Pablo M. Fernández (eds.), Zooarchaeology in the Neotropics: Environmental diversity and human-animal interactions (pp. 25-46), Cham, Suiza: Springer International Publishing.

Frontini, R., Bayón, C. y Vecchi, R. (2021). Fish capture strategies in Atlantic littoral of Monte Hermoso district (Pampean Region Argentina) during Middle Holocene. En J. B. Belardi, D. Bozzuto, P. M. Fernández, E. Moreno y G. Neme (Eds.), Ancien hunting strategies in southern South America (pp. 113-135), Cham, Suiza: Springer.

González, M., P. Escoteguy, M. Salemme, M. M. Frere, C. Weitzel y R. Vecchi. 2021. Assessing strategies for coypu hunting and use in the Salado River Depression (Buenos Aires province, Argentina). En J. B. Belardi, D. Bozzuto, P. M. Fernández, E. Moreno y G. Neme (Eds.), Ancien hunting strategies in southern South America (pp. 59-81), Cham, Suiza: Springer.

González Uriarte, M. (2002). Geoambientes del suroeste bonaerense. En M. del C. Vaquero (Comp.), Territorio, Economía y Medio Ambiente en el Sudoeste Bonaerense (pp. 463-483), Bahía Blanca, Argentina: EdiUns.

Hocsman, S., Martínez, J. G., Aschero, C. A. y Calisaya, A. D. (2012). Variability of Triangular Non-Stemmed Projectile Points of Early Hunter-Gatherers of the Argentinian Puna. En L. Miotti, M. Salemme, N. Flegenheimer y T. Goebel (Eds.), Southbound: Late Pleistocene Peopling of Latin America. Current Research in the Pleistocene (Special Edition) (pp. 63-67), Bryan: Estados Unidos: Center for the Study of the First Americans.

Hughes, S.S. (1998). Getting to the point: evolutionary change in prehistoric weaponry. Journal of Archaeological Method and Theory, 5 (4), 345-408.

Kaufmann, C., M. C. Álvarez, P. Messineo, M. P. Barros, M. Bonomo y G. Heider. (2021). Guanaco hunting strategies in the Southeastern Pampas during the late Holocene. En J. B. Belardi, D. Bozzuto, P. M. Fernández, E. Moreno y G. Neme (Eds.), Ancien hunting strategies in southern South America (pp. 83-112), Cham, Suiza: Springer.

Knecht, H. (1997). Projectile Technology. Nueva York, Estados Unidos: Plenum Press.

Lemonnier, P. (1992). Elements for an Anthropology of Technology. Museum of Anthropology Papers 88. Ann Arbor, Estados Unidos: University of Michigan.

Martínez, J.G. (2007). Ocupaciones humanas tempranas y tecnología de caza en la microrregión de Antofagasta de la Sierra, Puna meridional argentina (10000-7000 AP). Cazadores-Recolectores del Cono Sur, 2, 129-150.

Martínez, J. G., Caria, M., Mauri, E. y Mercuri, C. (2010). 
Puntas de proyectil líticas de colección. Aportes para la arqueología de tierras bajas (cuenca Tapia-Trancas, Tucumán. Argentina). En S. Bertolino, R. Cattáneo y A. Izeta (Eds.), La Arqueometría en Argentina y Latinoamérica (pp.189-196), Córdoba, Argentina: Universidad Nacional de Córdoba.

Mazzanti, D. L. (2006). La constitución de territorios sociales durante el Holoceno tardío. El caso de las Sierras de Tandilia, Argentina. Relaciones de la Sociedad Argentina de Antropología, XXXI, 277-300.

Messineo P. G. y Barros, M. P. (2015). Lithic raw materials and modes of exploitation in quarries and workshops from the center of the pampa grasslands of Argentina. Lithic Technology, 40 (1), 3-20.

Messineo, P. G. y N. Scheifler. (2016). Investigaciones arqueológicas de cazadores-recolectores en el sitio Laguna Cabeza de Buey 2 (centro de los pastizales pampeanos, Buenos Aires). Cincuenta años después de las Industrias Culturales definidas por Bórmida. Intersecciones en Antropología, 17, 213-226.

Nami, H. G. (1984). Algunas observaciones sobre la manufactura de las puntas de proyectil de EI Volcán. PREP Informes de Investigación, 1, 83-105.

Oliva, F., Ávila, J. D., Ayuso, M. P., Catella, L. y Gallego, M. 2006. Investigaciones arqueológicas en la cuenca del arroyo Chasicó y llanura adyacente, sudoeste de la provincia de Buenos Aires. Comechingonia, 9 (1), 123139.

Oswalt, W. H. (1976). An anthropological analysis of food-getting technology. Nueva York- Londres, Estados Unidos-Gran Bretaña: John Wiley \& Sons.

Pellegrin, J. (1991). Le Savoir faire: une très longue histoire. Terrain, 16, 106-113.

Politis, G. (2012). Las poblaciones prehispánicas. En H. Otero (Dir.), Historia de la Provincia de Buenos Aires 1. Población, ambiente y territorio (pp. 213-247), Buenos Aires, Argentina: Unipe-Edhasa,

Politis G. y Madrid, P. (2001). Arqueología Pampeana: Estado actual y Perspectivas. En E. Berberian y A. Nielsen (Eds.), Historia Argentina Prehispánica II (pp. 737-814), Córdoba, Argentina: Editorial Brujas.

Ratto, N. (1991). Análisis funcional de las puntas de proyectil líticas de sitios del sudeste de la Isla Grande de Tierra del Fuego. Arqueología, 1, 151-178.

Santos Valero, F. (2017). La gestión de rocas a través del tiempo: aportes al estudio de la tecnología lítica durante el Holoceno medio y tardio en el valle inferior del río Colorado (provincia de Buenos Aires, Argentina). Tesis Doctoral inédita. Olavarría: Facultad de Ciencias Sociales, Universidad Nacional del Centro de la provincia de Buenos Aires.

Scabuzzo, C., Frontini, R., Vecchi, R. y Bayón, C. (2016). Isótopos estables y dieta de los cazadores recolectores del sudoeste bonaerense (Argentina). Chungará, 48 (3), 383-395.

Scheifler, N. (2019). Ecología y subsistencia de los cazadores-recolectores en el campo de dunas del centro pampeano. Buenos Aires, Argentina: Sociedad Argentina de Antropología.

Shott, M. (1978). Arrowheads and atlatl darts: how the stones got the shaft. American Antiquity, 43, 461-472.

Shott, M. (1993). Spears, Darts and Arrows: Late Woodland Hunting Techniques in the Upper Ohio Valley. American Antiquity, 58 (3), 425-443.

Shott, M. (1997). Stones and Shafts Redux: The Metric Discrimination of Chipped-Stone Dart and Arrow Points. American Antiquity, 62, 86-101.

Thomas, D. H. (1978). Arrowheads and Atlatl Darts: How the Stones Got the Shaft. American Antiquity, 43 (3), 461-472.

Valverde, F. y Martucci, M. (2004). Estudio tecnotipológico de las puntas de proyectil del sitio Cueva El Abra (provincia de Buenos Aires). En G. Martínez, M. A. Gutiérrez, R. Curtoni, M. Berón y P. Madrid (Eds.), Aproximaciones contemporáneas a la arqueología pampeana. Perspectivas metodológicas, analíticas $y$ casos de estudio (pp. 419-434), Olavarría, Argentina: Facultad de Ciencias Sociales, Universidad Nacional del Centro de la Provincia de Buenos Aires.

Vecchi, R., Frontini, R. y Bayón, C. (2013). Paso Vanoli: una instalación del Holoceno tardío en valles fluviales del sudoeste bonaerense. Revista del Museo de La PlataAntropología, 13 (87), 77-93.

Vecchi, R., Frontini, R. y Bayón, C. 2019. Sitios de superficie en las lagunas del sudoeste de la provincia de Buenos Aires ¿Es posible aportar información sobre circuitos de movilidad? Trabajo presentado en el XX Congreso Nacional de Arqueología Argentina, Córdoba, Argentina, Ms.

Vigna, M., González, M. I. y Weitzel, C. (2014). Los cabezales líticos de la microrregión del río Salado bonaerense, Argentina. Diseños e historias de vida. Intersecciones en Antropología, 15, 55-69.

Weitzel, C., Flegenheimer, N., Martínez, J. G. y Colombo, 
R. J. Vecchi et al. | Revista del Museo de Antropología 14 (3): 07-20 | 2021

DOI: http://doi.org/10.31048/1852.4826.v14.n3.30256

M. (2014). Breakage patterns on Fishtail Projectile points: a comparative analysis of experimental and archaeological cases. Etnoarchaeology and Experimental Archaeology, 6, 81-102. 